Review

\title{
An Overview of Osteoporosis Management
}

Nathan S. Jiang ${ }^{1}$, Byron Newton ${ }^{1}$, Xuezhi Jiang ${ }^{1,2,3,}{ }^{*}$

1. The Reading Hospital/Tower Health; Departments of ObGyn, Reading, PA, US; E-Mails: 22njiang@student.dasd.org; Edwin.Newton@towerhealth.org; Daniel.Jiang@towerhealth.org

2. Sidney Kimmel Medical College at Thomas Jefferson University; Departments of ObGyn, Philadelphia, PA, US

3. Drexel University College of Medicine, Philadelphia, PA, US

* Correspondence: Xuezhi Jiang; E-Mail: Daniel.Jiang@towerhealth.org

Academic Editor: Ray Marks

Special Issue: $\underline{\text { Research on Bone Diseases in Older Adults }}$

OBM Geriatrics $\quad$ Received: June 28, 2021

2021, volume 5 , issue 4

doi:10.21926/obm.geriatr.2104181
Accepted: October 06, 2021

Published: October 19, 2021

\begin{abstract}
Osteoporosis is one of the most common disorders around the world. Osteoporotic fracture especially hip fracture are associated with an increased mortality rate in elders. However, elders with osteoporosis or at high risk of fractures remain largely underdiagnosed and undertreated. The screening, diagnosis, and treatment of osteoporosis must be improved to maintain pace with its fast-growing prevalence. This review will cover risk factors of osteoporosis, screening and diagnosis tools, newfound advancements, current medical treatments including options for special populations of concern, and future research directions.
\end{abstract}

\section{Keywords}

Osteoporosis; fractures; elders 


\section{Introduction}

Osteoporosis is a severe bone disease that is characterized by low bone mass, abnormally deficient bone mineral density, and the deterioration of the microarchitecture of the bones. Osteoporosis most commonly results in bone fragility and a dramatically increased risk of fractures often seen at the femur neck area of the proximal hip or at the lumbar spine [1]. There are two primary classifications of osteoporosis: primary and secondary. Primary osteoporosis can be defined as osteoporosis resulting from naturally occurring aging and sex hormone deficiency [2]. Moreover, primary osteoporosis can be classified into two subgroups: involutional osteoporosis Type I, also known as postmenopausal osteoporosis and most often caused by estrogen deficiency, and involutional osteoporosis Type II, also known as senile osteoporosis due to aging and more fragile, trabecular and cortical bones [3]. Secondary osteoporosis can be defined as osteoporosis ensuing from certain medical conditions or diseases, various comorbid illnesses and specific medications such as corticosteroids and antiepileptic drugs.

Osteoporosis is one of the most common disorders around the world. In the United States alone, approximately 10 million men and women sufferfrom osteoporosis [4] and more than 1.5 million fractures annually can be attributed to osteoporosis. The most common fracture locations are vertebral $(650,000)$, the distal forearm $(200,000)$, and the hip $(250,000)$ [5]. Over 200 million people worldwide suffer from osteoporosis [5] and, according to thelnternational Osteoporosis Foundation, 1 in every 3 women over the age of 50 and 1 in every 5 men globally will experience osteoporosis at some point in their lives [3]. In the United States, osteoporosis-related direct and indirect costs exceed $\$ 10$ billion annually [6], the majority of which comes from hip fracture surgery and recovery [5]. Hip fractures alone are associated with $15-20 \%$ increased mortality rate within one year, with a higher mortality rate in men than in women. Hip fractures make the patient susceptible to other diseases like pneumonia and thromboembolic disease secondary to chronic immobilization [3]. By the year 2040, osteoporosis-related costs are expected to reach $\$ 240$ billion because of heightened life expectancy of the global population [7].

The screening, diagnosis, and treatment of osteoporosis must be improved to maintain pace with its fast-growing prevalence. Diagnosis of osteoporosis is often delayed. For instance, osteoporosis is rarely even diagnosed afterthe first occurrence of vertebral fracture due to two main reasons. First, vertebral fractures are frequently not a recognizable event in clinical settings. Second, many radiologically evident vertebral fractures go unreported [8]. Although screening modalities remain a plenty, osteoporosis is still underdiagnosed and undertreated worldwide. Curtis et al. analyzed records of 9,876 male Medicare patients who had suffered an osteoporotic fracture between January 2010 and September 2014, and found that only 6\% had received any screening or treatment for osteoporosis within the two years prior to their fracture despite $62.8 \%$ having had a history of musculoskeletal pain. Overall, $2.8 \%$ of the patients were diagnosed but not treated, $2.3 \%$ were treated but not diagnosed, and only $2.1 \%$ were both diagnosed and treated in the year prior to the fracture. In the year after the fracture, only about $10 \%$ of patients underwent bone mineral density (BMD) testing with only $9 \%$ receiving a treatment for osteoporosis. About $7 \%$ had a second fracture in the year following their first injury [9]. Earlier and more effective screening tests along with proper diagnoses would help improve quality of life for patients with osteoporosis and reduce overall health care cost. As more is understood of bone morphology and osteoporosis, scientists will have made major innovative leaps in its' diagnosis and treatment including the utilization of 
noninvasive dual-energy $x$-ray absorptiometry (DXA), long-term medical algorithms to better identify and prevent fractures, and effective medications like bisphosphonates. This review will cover pathogenesis and risk factors of osteoporosis, screening and diagnosis tools, newfound advancements, current medical treatments including options for special populations of concern, and future research directions.

\section{Pathogenesis of Osteoporosis}

The fundamental pathogenetic mechanisms underlying osteoporosis include a). failure to achieve optimal peak bone mass during growth and development, which is largely determined by our genes, nutrition (i.e., calcium and vitamin $D$, etc.), and lifestyle; b). excessive bone resorption resulting in decreased bone mass and skeletal microarchitectural deterioration; $c$ ). an inadequate bone formation response to increased resorption during the process of bone remodeling, which is an essential component of the pathogenesis of osteoporosis [10]. The regulation of bone remodeling involves not only the osteoblastic and osteoclastic cell lineages but also other marrow cells, in addition to the interaction of systemic hormones (i.e. estrogen), local cytokines, growth factors, and transcription factors [10]. Furthermore, many genes have been identified as possible candidates for the regulation of bone mass and susceptibility to osteoporosis [11].

RANKL is a ligand expressed on osteoblasts and T cells. It binds the receptor RANK on osteoclast precursors, and stimulates their differentiation and activity. The RANKL/RANK interaction is required for osteoclasts formation, differentiation, and activation, hence, represents a final common pathway in osteoporosis pathogenesis for any pathogenetic factor triggering excessive bone resorption.

The therapy of osteoporosis is directed at the major pathogenetic mechanisms outlined above. Intervention for the first pathogenetic mechanism, failure to achieve optimal peak bone mass, should be applied during skeletal growth and development. Moreover, adequate calcium and vitamin $D$ intake along with appropriate physical activity may not only help maximize peak bone mass but also prevent or slow bone loss and reduce risk of osteoporotic fracture throughout life. Pharmacotherapy for osteoporosis focusing on the second mechanism, such as bisphosphonates and estrogen, aims to reverse excessive bone resorption. Treatment for the third pathogenetic mechanism, impaired bone formation, is as effective as antiresorptive agents in fracture reduction.

\section{Risk Factors}

Many risk factors for osteoporosis exist in the general population, including but not withstanding age, nutritional diet, demographics, and steroids use. Most of these risk factors apply to both sexes; however, a variety of risk factors are gender-specific. A good understanding of modifiable risk factors of osteoporosis helps prevent bone loss and osteoporotic fractures.

Age is a predominant risk factor for osteoporosis regardless of sex. Progressive decrease in BMD with age is one of the major risk factors for fractures. Accelerated loss among women during the perimenopausal period $[12,13]$ begins between ages 40 and 44 , peaks between ages 50 and 54 , and then stabilizes. This accelerated loss is a major determinant and a difference in patterns of bone loss between women and men. A second period of accelerated bone loss in women begins at age 70 in the total hip evident by the rate of bone loss after age 75 years being the same as that at age 50-54 [14]. This second period of rapid bone loss among women, and to a lesser extent among men, 
may be attributed to the increased incidence of hip fractures among elderly patients. When age is considered, fracture location in the skeletal system diverges into two age-related patterns. The first fracture pattern is primarily observed at sites that contain high levels of trabecular bone [5] such as vertebrae and distal forearm (Colles' fracture). Both fractures increase soon after menopause and continue to rise with age; however, Colles' fracture incidence reaches a plateau at age 65 [5]. The second pattern is observed in sites containing similar levels of trabecular and cortical bone such as in the hip. These fractures slowly increase in incidence with aging, until age 65-70, when they exponentially increase in both sexes.

Numerous studies have shown that nutritional deficiency and a sedentary lifestyle may serve as risk factors for osteoporosis, regardless of sex. Consuming an excess of junk food results in a lessened intake of vitamins like vitamin $\mathrm{K}$ (particularly vitamin K2) [15]. This deficiency can severely impair the calcium removal process and increase the riskof vascular calcification [15]. An adequate level of calcium intake has been proven to increase and maintain bone mass with a proper amount of vitamin $D$ being demonstrated to be beneficial to intestinal absorption of calcium [16]. A study performed in the general Japanese population reported that avoiding sunbathing and eating lesser fish products resulted in vitamin D deficiency [17]. Thus, a healthier lifestyle, as opposed to lifestyle characterized by nutritional deficiency, may eliminate this particular risk factor and reduce the possibility of osteoporosis.

Alcohol consumption has been demonstrated as a risk factor for osteoporosis in both sexes. An inverse relationship was established between light alcohol consumption and hip fracture risk from osteoporosis. Heavy alcohol consumption was positively associated with a higher risk of hip fracture from osteoporosis [18]. The Framingham Osteoporosis Study has shown that women between the ages of 67 and 90 whose alcohol consumption averaged greater than 3 ounces/day experienced a higher level of bone loss than those women who had minimal alcohol consumption [19]. Thus, a higher level of alcohol consumption can be considered to be a detriment to bone health specifically in the cortical and trabecular compartments at the distal radius in males and in the trabecular and distal tibia compartments in females [15].

Although evidence is less affirmative on a causal relationship between smoking and osteoporosis, cigarette smoking is considered to be a risk factor for osteoporosis regardless of sex. In women, nicotine is known to inhibit the primary function of the aromatase enzyme which serves to produce estrogens by aromatizing androgens. Consequently, nicotine reduces circulating estrogen levels and leads to increased risk of bone loss. According to Kline et al., current smoking is associated with a $15 \%$ increase in median follicle-stimulating hormone (FSH) which may reflect a decreased circulating estrogen level [20]. Kralland et al. reported that the overall annual bone loss was greater in smokers than that in nonsmokers at locations such as the femoral neck, os calcis, and the spine [21]. The emerging evidence suggests that smoking has a negative impact on the risk and treatment of osteoporotic fractures [22].

A previous history of fractures is considered to be a significant risk factor for osteoporosis in both males and females. A study performed by Morin et al. examined the significance of previous fractures in osteoporosis diagnosis and future fractures in 40,000 women with a mean age of 64 years [23]. These women all previously had some type of non-traumatic fracture prior to BMD measurement at sites like the hip, the forearm, the humerus, and the clinical spine. After BMD measurement, 2,501 (6\%) women sustained major osteoporotic fractures in the forearm, humerus, hip, and spine during a period of 5.3 years. About $13 \%$ of the study population were diagnosed with 
osteoporosis based on femoral neck BMD. Women who had suffered previous hip, pelvis, or humeral fractures had the lowest mean femoral neck T-scores suggesting possible osteopenia [23]. Previous fractures of other bones such as the patella, ribs, carpal, tibial, and tarsal/metatarsal sites showed significant association with T-scores in the osteoporosis range. It was concluded that nontraumatic fractures in women are associated with osteoporosis at the femoral neck and future osteoporotic fracture risk independent of BMD [23].

Several inflammatory diseases such as rheumatoid arthritis, systemic lupus erythematosus, inflammatory bowel disease, celiac disease, and chronic obstructive pulmonary disease have been associated with bone resorption. Inflammation may increase bone loss via the bone remodeling cycle regulated by osteoblasts and osteoclasts. The link between osteoclast, macrophage colony stimulating factor and pro-inflammatory cytokines, such as tumor necrosis factor-alpha and interleukin-1 explain the association between inflammation and osteoporosis [24]. Diabetes Mellitus (DM), particularly type $1 \mathrm{DM}$, and hyperthyroidism often have poorer bone quality and an increased risk of fractures. While several theories exist based on cellular models explaining the link of these diseases with osteoporosis, these disorders are thought to trigger an imbalance of boneeroding activity by the osteoclasts, regardless of the complexity of osteoporosis pathogenetic pathways.

Medications such as glucocorticoids are one of the major risk factors for bone loss and osteoporotic fractures. Glucocorticoids primarily affect and alter osteoblasts; and, to a lesser extent, osteoclasts in the bones. Glucocorticoids reduce the mRNAs for type Icollagen and the principal non-collagenous protein of the bone, and reduce osteocalcin levels: the hormone that serves as a calcium-binder and aids in bone formation [25]. Glucocorticoids may directly inhibit osteoblast replication and differentiation as well [26]. Higher doses of glucocorticoids are associated with rapid bone loss, affecting mostly the axial and appendicular skeleton, but also at the spine [27]. A prospective study by Laan et al. has demonstrated that 20 weeks of glucocorticoid treatment with a mean dose of $7.5 \mathrm{mg} /$ day resulted in an $8 \%$ trabecular bone loss in the lumbar spine [28]. In addition, histomorphometric studies have shown that glucocorticoid treatment results in a significant decrease in osteoid seams and mean wall thickness [29], with the overall bone loss demonstrated to be 30\% [26]. Glucocorticoids are associated with a marked increase in fractures in both males and females with fracture rates averaging 30\% in adults with 5 years or more of glucocorticoid treatment [21]. The risk of hip fractures double in patients taking glucocorticoids compared to those with rheumatoid arthritis [29].

Unique to each sex is the predominance of their own sex hormone: androgen for males and estrogen for females. Androgens are especially vital to proper bone growth and bone mass density in developing males, and estrogens are also essential for the inhibition of bone remodeling, the maintenance of bone metabolism, and bone growth in females. Thus, hypogonadism has been shown to be a risk factor for bone loss and secondary osteoporosis in males and females. An MrOS study that followed the incidence of osteoporosis fractures in older men (aged $\geq 65$ years) from Sweden, the United States and Hong Kong for a mean duration of 5.7 years suggests a significant association between low total testosterone levels and incident falls in older men [30]. The MrOS Sweden study found that lower levels of free testosterone were associated with a much higher fracture risk in men and estrogen positively correlated with BMD in all locations including lumbar spine [31]. In the Dubbo study, Australian men over the age of 60 years sustained less BMD when bioavailable E2 and testosterone levels were decreased [32]. The relationship between decreased 
levels of androgens in males and osteoporotic fractures can be explained by testosterone as it plays an independent and major role in muscle strength and peak performance thus guarding against fractures and falls [33]. The role of estrogen deficiency in the development of osteoporosis in females has been documented. A study performed by Garnero et al. on a sample of 653 French women found that menopause resulted in a net increase in bone resorption with bone formation markers increased by about $45 \%$ and bone resorption markers increased by about $90 \%$ [34]. In addition, estrogen deficiency in females resulted in increased bone sensitivity to parathyroid hormone (PTH) and other bone resorption-inducing hormones [35]. It is well documented that young, estrogen-deficient women with primary ovarian insufficiency (POI) have lower BMD compared to regularly-menstruating women [36]. Thus, similar to findings regarding androgens' role in osteoporosis in older and testosterone-deficient males, estrogen deficiency has been demonstrated to cause increased bone loss and osteoporosis in young women with POI, early menopausal and postmenopausal women. The issue of androgen and estrogen deficiency must be proactively addressed to reduce or prevent the risks of osteoporosis and fractures.

\section{Screening and Diagnosis for Osteoporosis}

Despite the number of osteoporosis screening guidelines established and available worldwide, a universal consensus has not been reached. As mentioned previously, patients with osteoporosis or at risk of fractures remain largely underdiagnosed and undertreated. About $80 \%$ of patients with history of fragility fractures (femoral or vertebral), or chronic treatment with glucocorticoids did not receive a correct diagnosis or adequate treatment for osteoporosis thus significantly increasing risk for future fractures [37]. Although some guidelines vary on the age cutoff for when screening should be implemented in women, the general consensus is that all women over the age of 65 years should be screened for osteoporosis. For women of ages less than 65 years, the United States Preventive Task Force (USPSTF) recommends that BMD screening should be performed if women possess a 10year fracture risk equivalent to or greater than the fracture risk for older women aged over 65 years [38]. The USPSTF initially proposed a 10-year major osteoporotic fracture (MOF) risk of $9.3 \%$ or above calculated using the Fracture Risk Assessment Tool (FRAX, www.shef.ac.uk/FRAX) without $B M D$ as a threshold for BMD screening in postmenopausal women between the ages of 50 and 64 [38]. Multiple studies found this threshold associated with a low sensitivity ranging from $24-40 \%$ [39-42]. The threshold was lowered to $8.4 \%$ in 2018 which only increased sensitivity of detecting younger osteoporotic women (<65 years) for BMD testing by $3 \%$ [42]. The National Osteoporosis Foundation (NOF) recommends that BMD screening should be implemented for postmenopausal women between the ages of 50 to 60 depending on their specific risk factor profile [43]. For instance, BMD testing should be performed in postmenopausal women with previous adult fractures to ascertain the nature of previous fractures and for the possible presence of osteoporosis. Similar to the NOF, most medical societies recommend a risk factor-based approach to osteoporosis screening; however, this poses challenges for clinicians since more than 30 risk factors have been listed in the guidelines with risk factors varying widely among different guidelines. From a clinical perspective, Simple Calculated Osteoporosis Risk Estimation (SCORE $\geq 6$ ) and Osteoporosis Self-assessment Tool $(\mathrm{OST}<2)$ are two practical BMD screening tools for postmenopausal women with comparable sensitivities ranging from $89-92 \%$ and $85-97 \%$, respectively [44-46]. Both tools can be easily accessed online and the OST may be more efficient since it only takes into account age and weight 
[47]. Screening guidelines for men are much less complex compared with women. According to the Endocrine Society, which utilized the GRADE system (Grading of Recommendations, Assessment, Development, and Evaluation), men over the age of 70 and men aged 50-69 years with significant risk factors for osteoporosis or fracture should undergo osteoporosis screening using central dualenergy $x$-ray absorptiometry (DXA) [48].

The diagnosis of osteoporosis is most commonly established through BMD measurement in total hip, femoral neck, and lumbar spine areas. BMD refers to grams of calcium per square centimeter $\left(\mathrm{cm}^{2}\right)$ of bone in consideration. Regarding specific measurement units, the T-score can be described as the difference between the BMD of the patient and the mean BMD of a young adult reference population divided by the mean standard deviation (SD) of the reference population in question [43]. According to the World Health Organization (WHO) diagnostic classification, the presence of osteoporosis in a patient is defined as BMD that is more than 2.5 SD below the young adult mean normal BMD, or a T-score <-2.5 [43]. Moreover, osteoporosis exists when there has been a previous osteoporotic fracture. Osteopenia or low bone mass is established in patients with BMDs between 1 and 2.5 SD below the young adult mean normal BMD, or a T-score between -1 and -2.5 [40]. Normal BMD level is defined in healthy adultsas a T-score between -1 and 1 SD. Severe or established osteoporosis is marked by 2.5 SD or more below the mean level for the reference population with established fractures or a T-score at or below -2.5 with one or more fractures [43]. Generally, fracture risk increases 1.5 to 3-fold as each SD of BMD decreases beneath the reference population [49]. It is therefore evident that BMD measurement is an optimal method to diagnose osteoporosis in the majority of patients.

Numerous methods to measure and analyze BMD in patients exist and are widely utilized such as radiographic absorptiometry, single-energy x-ray absorptiometry, quantitative ultrasound,and quantitative computed tomography. However, the most well-documented and proven method of clinically measuring BMD derives from DXA as it provides the best predictor of osteoporosis and has been repeatedly endorsed as the "gold standard" for osteoporosis screening and diagnosis [3]. DXA measurements should be performed in the hip, femoral neck, and/or lumbar spine to achieve the most accurate diagnosis. In patients over the age of 65, it is best for DXA to be performed at the proximal femur area to counteract the bias that may arise from osteoarthritis of the column [50]. The actual execution of DXA takes only 3 to 7 minutes with a delivery of low effective radiation doses ranging from 0.009-0.027 mSv; of note, the worldwide average effective dose from natural background radiation is $2.4 \mathrm{mSv} /$ year [51]. DXA utilizes a unique method that employs a high energy and low energy beam for BMD measurement with the difference in soft-tissue and bone penetration of these two energy beams leading to the BMD calculations [43]. Advantages of DXA in comparison to other BMD measurement methods for the diagnosis of osteoporosis include its propensity for more accurate identification of patients with fracture risk. This assertion is supported by the Study of Osteoporosis Fractures (SOF) performed in the late 1980s where 9,704 white women aged 65 or older were tested for abnormal BMD [52]. A follow-up study found that there was a strong correlation between hip BMD and hip fracture risk prediction [52]. DXA has been endorsed by the NOF and USPSTF as the most optimal method to measure BMD in patients with risk of osteoporosis. To ensure proper measurements and data collection, it is imperative for DXA testing to be performed by licensed and trained technicians with accurately working instruments and tools.

The most serious consequence of osteoporosis is the potential risk of fractures. An effective fracture prediction tool would help reduce risk of future fracture in individuals as well as fracture 
related morbidity and mortality by early intervention with osteoporosis therapy. Prior osteoporotic fracture is a strong predictor of subsequent fracture. In women $\geq 65$ years who sustained a clinical vertebral or nonvertebral fracture, cumulative risk of subsequent fracture was $10 \%, 18 \%$, and $31 \%$ at 1,2 , and 5 years after the first fracture, respectively [53]. The most well-known algorithmic tool for fracture prediction is known as FRAX. FRAX primarily uses osteoporosis risk factors to predict the 10-year probability of a major osteoporotic fracture (MOF) most commonly in the hip, vertebrae, forearm/wrist, and/or proximal humerus [3]. According to the NOF, if a FRAX calculated 10-year risk of MOF was greater than or equal to $20 \%$, the patient is at high risk for fracture and prompt medical attention is warranted. Furthermore, a 10 -year hip fracture probability of $3 \%$ or greater should be an indication for treatment intervention [54]. Clinical risk factors that FRAX utilizes consist of current age, sex, a prior osteoporotic fracture (including clinical and asymptomatic vertebral fractures), a history of parental hip fracture, femoral neck BMD, a low BMI (less than $21 \mathrm{~kg} / \mathrm{m}^{2}$ ), oral glucocorticoids greater than or equal to $5 \mathrm{mg} / \mathrm{d}$ of prednisone for $>3$ months, rheumatoid arthritis, any secondary risk factors of osteoporosis (type I diabetes, chronic malnutrition, chronic liver disease, osteogenetic imperfecta), history of smoking, and high alcohol intake (3 or more units per day). Vertebral imaging also proves useful when utilizing FRAX to diagnose osteoporosis as vertebral fractures can remain asymptomatic and undetected for long periods of time. It is important to recognize that fracture probability varies greatly in different regions of the world due to differences in fracture risk and mortality. These differences require the FRAX model to be calibrated to national fracture and mortality rates in a respective country to define a unique intervention threshold specific to the particular population [55].

However, the limitations of FRAX should not be overlooked. For a 30-year old patient at potential risk of fracture, FRAX cannot be used to ascertain an accurate prediction of fracture risk because the patient is outside of the optimal age range of 40 to 90 years. Fracture incidence varies between ethnic groups; however, ethnicity is not a variable in the FRAX model. Ethnicity-specific FRAX models are only available in the USA, South Africa and Singapore. Variations in ethnicity-specific risk often exceed those in sex-specific risk; therefore, failure to calibrate for ethnicity in FRAX would have greater adverse consequences than failure to calibrate for sex [56]. Moreover, FRAX is not validated for use with total hip or lumbar spine BMD or for use with patients currently undergoing osteoporosis treatment at the time of testing. Previous falls are not included as a risk factor for fractures because the cohort data that FRAX was tested on was not suitable for analysis of falls. There also has not been enough evidence to demonstrate that pharmacological intervention based on previous fall history will reduce fracture risk. One final limitation that is unavoidable is the constant changes in fracture rates and life expectancy which force all models, including FRAX, to vary its components to better reflect new lifestyles. A systematic review and meta-analysis analyzed the predictive accuracy of FRAX US intervention threshold ( $20 \%$ for MOF and $3 \%$ for hip fracture) in detecting women at risk of fractures for treatment intervention. It was found that the FRAX US intervention threshold has a low sensitivity in detecting women with risk of fractures $(10.25 \%$ for MOF and $45.7 \%$ for hip fracture, respectively) [57]. The Trabecular Bone Score (TBS) is a surrogate of bone microarchitecture derived from lumbar spine DXA imaging and has been shown to be predictive of fragility fracture independent of FRAX, clinical risk factors, and BMD. The use of TBSadjusted FRAX has been shown to be more accurate in predicting 10-year fracture probabilities than the use of the FRAX tool alone [58]. The utility of TBS-adjusted FRAX was found to be greatest in younger women (aged $<65$ years) whose FRAX calculated 10 -year fracture probabilities are close to 
an intervention threshold. The calculation would aid in clinical decision making on whether treatment is warranted or not $[59,60]$. Besides utilizing the FRAX with or without TBS for identification of candidates for pharmacological intervention, treatment decision making should also be individualized to take into account other risk factors such as BMD values (i.e. T-score <-2), risk of falls, diabetes, untreated primary ovarian insufficiency or early menopause, chronic kidney disease, and family history of non-hip fragility fractures.

Osteoporosis diagnosis may also utilize recent advances in tools for more effective screening and diagnosis: computed tomography (CT) scans can overcome the limitations and weaknesses of methods like DXA and FRAX. The multidetector CT scan most commonly and effectively used in osteoporosis diagnosis is volumetric quantitative CT (VQCT) [61]. This mode of imaging produces three-dimensional images allowing for separate analysis of trabecular and cortical bone. This is one of the advantages of CT scans over tools like DXA as two-dimensional single slice applications are upgraded to three-dimensional products. VQCT analyzes the spine, hip, forearm, and tibia using whole body clinical and separate peripheral scanners. Slice thickness of vQCT usually is greater than $1 \mathrm{~mm}$ with the plane pixel size being greater than $\times 0.3 \mathrm{~mm}^{2}$ [62]. Recent advances in vQCT have stemmed from the original measurement of QCT of trabecular BMD from single transverse slice. Three-dimensional data from VQCT have raised new questions and concerns about reliability of certain aspects of VQCT scans: specifically, the location of volume of interest (VOI) of longitudinal scans. Recent advances have suggested follow-up scans or the repositioning of VOI relative to a coordinate system(s). vQCT can also predict and determine fracture risk by evaluating geometrical parameters such as cross-sectional areas of the spine and the hip. A study that utilized crosssectional vQCTs determined that the cross-sectional area of women increases at a slower rate than that of men and bone mass loss occurs at a more rapid pace. The resulting breakthroughs in this study may provide additional insights into the roles of cross-sectional vQCTs in fracture risk predictors and may allow for a more nuanced understanding into osteoporosis and fracture risk. VQCT scans also provide valuable information regarding the extent to which ethnicity affects fracture risk. By also utilizing cross-sectional vQCTs, the Osteoporosis Fractures in Men Study (MrOS) [63] found that cross-sectional areas of the femoral neck and shaft can grow and/or thin as a patient ages. Ethnic variability exists with increased femoral neck and lumbar spine volumetric BMD and decreased cross-sectional areas differing in African Americans. Results that explain ethnic differences originating from the power of VQCT can provide fascinating epidemiological knowledge and add to the knowledge of osteoporosis. In general, advances in vQCT prove advantageous over other methods of screening and diagnosis for osteoporosis in that data is more precise and readily available for observation and analysis; however, a lack of commonality and accessibility of vQCT persists.

\section{Treatment}

Osteoporosis therapies should have the following goals: the reduction of risk or complete prevention of future fractures, the maintaining of quality of life and general lifestyle, and the relieving of pain and symptoms of skeletal deformity. Osteoporosis treatment can be categorized into either pharmacological or non-pharmacological therapies. This section will outline current treatments options for males and females, present concerns in special population groups, and highlight current research advances and future research direction in osteoporosis therapy. 
Non-pharmacological therapy consists of maintaining a healthy quality of life to prevent osteoporosis. First, it is highly recommended to achieve adequate calcium and vitamin $D$ intake and supplementation. Studies have shown that in recent years, the rate of calcium and vitamin $D$ deficiency in the adult population has increased at an alarming pace in part due to lactose and other intolerances in adults [64]. Moreover, the Institute of Medicine (IOM) recommends that for men 50-70 years of age, daily calcium intake should range up to $1000 \mathrm{mg}$. For women 51 years or older and men 71 years or older, daily calcium intake should range upto $1200 \mathrm{mg}$ [4]. An inadequate calcium intake warrants calcium supplementation. Supplements like calcium carbonate and calcium citrate can be taken daily to maintain healthy bone mass, but excessive or improper dosage can prove harmful as calcium carbonate can result in bloating and gas. Vitamin $D$ also plays a vital role in maintaining healthy bone status, regulating calcium metabolism and absorption, and reducing fracture risk. The IOM recommends that for men and women aged 51-70 years of age, daily vitamin D intake shouldrange up to $600 \mathrm{IU}$. For men and women aged over 70, daily vitamin D intake should range up to $800 \mathrm{IU}$ [4]. For patients with insufficient vitamin D intake due to lack of dairy consumption or sun exposure, daily vitamin D intake should range from 1200-2000 IU [4]. Excessive vitamin $D$ intake can result in adverse consequences such as kidney stones and hypercalcemia [65].

Proper exercise and physical activity are other proven non-pharmacological methods for osteoporosis management. Daily physical activity can prove effective in slowing down BMD loss as one ages [66]. An example of adequate physical activity is a walking session of 30 to 40 minutes which is helpful in maintaining BMD, balance, and prevention of fracture risk [3]. Strength of hand grip has been associated with radius BMD [67]. Similarly, lumbar spine BMD was found to be associated with back strength [68]. Hence, it is evident that a healthy daily physical activity does have lasting impact on osteoporosis prevention.

For patients with low bone mass or osteoporosis who regularly consume an excessive amount of alcohol, this intake must be cut sharply to preserve bone health and lessen risk of fracture. Data from Kanis et al. have shown that alcohol intake above 2 units daily was associated with an increased risk of any osteoporotic fracture (risk ratio $[R R]=1.38 ; 95 \% \mathrm{Cl}, 1.16-1.65$ ) and hip fracture risk ratio $(\mathrm{RR}=1.68 ; 95 \% \mathrm{Cl}, 1.19-2.36)$ [69]. Patients with osteoporosis should consider limiting alcohol consumption to no more than 7 drinks per week that encompass wine, liquor, and beer.

Pharmacological therapy can be categorized into two main types: antiresorptive and anabolic. One of the most common antiresorptive agents are bisphosphonates. These are synthetic compounds that primarily inhibit osteoclast resorption and activation along with any potential calcification on the bone [3]. Bisphosphonates have been recommended as first-line osteoporosis treatment by most osteoporosis societies. Bisphosphonates can result in a $70 \%$ reduction in vertebral fractures and $40 \%$ to $50 \%$ reduction in hip fractures [70]. Bisphosphonates include alendronate (Binosto, Fosamax), ibandronate (Boniva), risedronate (Actonel, Atelvia) and zoledronic acid (Reclast, Zometa). Risedronate reduces both hip and vertebral fractures in a wide range of postmenopausal osteoporotic women. A study performed by Ringe et al. analyzed the effects of risedronate in a sample size of 580 men with both primary and secondary osteoporosis [71]. The study concluded that risedronate in males significantly increased BMD in the lumbar spine area (average of $4.7 \%$ ), hip (average of $2.7 \%$ ), and femoral neck area (average of $1.8 \%$ ) compared with the control [71]. In addition, risedronate (oral, given weekly or monthly) was associated with a $36 \%$ risk reduction in vertebral fracture, $26 \%$ in hip fracture, and $20 \%$ in non-vertebral fracture [72]. Alendronate (5-10 mg daily dose) has been tested as a selective inhibitor of bone resorption and 
was found to increase lumbar spine and total hip BMD by $4 \%$ and $7 \%$, respectively, after 2 years of therapy [6]. Alendronate (oral, given weekly) was associated with a $44 \%$ risk reduction in vertebral fracture, $40 \%$ in hip fracture, and $17 \%$ in non-vertebral fracture [72]. As with most bisphosphonates, alendronate is suitable in postmenopausal women with osteoporosis, women $<60$ years of age with osteopenia, and women who have already suffered from an osteoporosis-induced fracture [6]. The Endocrine Society 2012 guidelines recommend that generic alendronate should be initiated for most men who are candidates for pharmacological therapy due to increased fracture risk since there has been extensive experience established regarding its use as well as its availability at a low cost [48]. Ibandronate (oral, given monthly; Intravenous, given quarterly) was associated with a $31 \%$ risk reduction in vertebral fracture [72]; however, there has been no definitive evidence presented that ibandronate has a significant alleviating effect on non-vertebral fracture risk or hip fractures thus it is not a first-choice bisphosphonate option. Zoledronic acid (Intravenous, given annually) was associated with a $56 \%$ risk reduction in vertebral fracture, $42 \%$ in hip fracture, and $18 \%$ in nonvertebral fracture [72]. Although Zoledronic acid is not recommended as a first choice bisphosphonates, it is considered a first-line therapy in the following four subgroups: 1-secondary prophylaxis of hip fractures, 2-men with peptic ulcer disease, gastroesophageal reflux, malabsorption syndromes, cognitive dysfunction of different etiologies, and noncompliance with oral agents; 3- men with nonmetastatic prostate cancer; and 4-HIV-infected patients [73]. In general, bisphosphonates are an excellent option for osteoporosis treatment given their well-tested nature and rate of success in a wide range of patients.

Denosumab is another option for therapy that is classified as a human monoclonal antibody that inhibits RANKL. This agent is used for preventing fractures in patients with a high or abnormally high fracture risk (including postmenopausal women) or patients who have failed or are intolerant to other available osteoporosis therapies. Denosumab, derived from cDNA sequencing research on fetal rat intestine by Amgen in 2000, is a relatively new medication for the treatment of osteoporosis and glucocorticoid-induced osteoporosis [70]. One of the most influential trials that tested the effectiveness of denosumab was the FREEDOM trial [74] which studied 7,868 postmenopausal women with osteoporosis between the ages of 60 to 90 years and administered $60 \mathrm{mg}$ of either denosumab or placebo. Results indicated that denosumab was associated with a $68 \%$ and $39 \%$ reduction in vertebral and hip fractures, respectively. It is evident that denosumab is an effective medication for osteoporosis due to the reduction of vertebral, nonvertebral, and hip fractures.

A somewhat outdated therapy for osteoporosis treatment involves calcitonin. Calcitonin is a polypeptide hormone that specifically targets osteoclasts by binding them and thus preventing their proper functioning. Primarily, it is used for the prevention of vertebral fractures in postmenopausal women. Data on calcitonin effectiveness showed daily doses of $200 \mathrm{IU}$ in one study resulting in a $33 \%$ of reduction in vertebral fractures [4]. It is approved by the FDA for managing women who are at least 5 years postmenopausal and those in who other alternatives therapies are contraindicated. Primarily, calcitonin is administered in an intranasal preparation (200 IU daily, one spray per nostril). However, its usage has significantly declined in the last number of years due to being less effective in reducing fractures compared to other medications, its potentially increased cancer risk, and side effects including skin rashes, nosebleeds, and nausea/vomiting.

Teriparatide is an anabolic agent approved for use in postmenopausal women with osteoporosis who have not responded well to other forms of therapies or have a much higher risk of fractures [3]. Specifically, teriparatide is used to increase BMD and bone strength which is the most effective 
method to decrease elevated vertebral and hip fracture risk. Teriparatide can be used in both men and women to treat glucocorticoid-induced osteoporosis as well. However, the aforementioned drugs do have their limitations. Teriparatide has been linked to osteosarcoma in rodent trials [70], which leads to caution and limitation regarding its usage. Since patients who have had prior radiation therapy have an increased risk of developing a radiogenic second malignant neoplasm, including osteosarcoma $[75,76]$, Teriparatide should not be prescribed to those who have had prior external beam or implant radiation therapy [77].

Bone loss along with a raised fracture risk has been linked to hormonal deficiencies in both men and women. It is for this reason that hormonal therapy targeting estrogen, in women, and testosterone, in men, has been approved as an effective treatment for osteoporosis. In postmenopausal women with estrogen deficiency, estrogen therapy has been noted to be one of the most potent osteoporosis therapies [6]. Estrogen therapy functions through its antiresorptive properties preventing bone resorption and restoring bone remodeling which serves to reduce the risk of vertebral and hip fractures. The Woman's Health Initiative (WHI) can be regarded as the most authentic randomized clinical trial on the effect of estrogen therapy on postmenopausal women. The WHI Hormone Therapy (HT) trial recruited 16,608 postmenopausal women from the ages of 50 to 79 years, and tested dosages of conjugated equine estrogen (CEE, $0.625 \mathrm{mg} / \mathrm{d}$ ) paired with medroxyprogesterone acetate (MPA, $2.5 \mathrm{mg} / \mathrm{d}$ ), or CEE alone vs. placebo [78]. Researchers found that CEE+MPA was associated with a $34 \%$ reduction in hip and clinical vertebral fractures, and a $24 \%$ reduction in total osteoporotic fracture [78]. CEE alone was associated with a 39\% reduction in hip fractures, $38 \%$ in vertebral fractures, and $30 \%$ in total fracture [79]. An additional study also showed that oral estrogen ( $1500 \mathrm{mg} /$ day) corresponded with a $10.6 \%$ increase in vertebral BMD, and a $5.5 \%$ increase in femoral neck BMD in postmenopausal women [80]. In addition, ultra-low dosages of estrogen may also help in preventing BMD loss in postmenopausal women. A study by Ettinger et al. showed that dosages of $0.014 \mathrm{mg} / \mathrm{d} 17 \beta$-Estradiol resulted in an increase of $2.6 \%$ in lumbar spine BMD and a $0.4 \%$ increase in total hip BMD [81]. It is evident that estrogen is effective in improving BMD and reducing risk of fractures; however, the initial safety report from the WHI HT trials published in 2002 [82] and 2004 [79] included an increased risk in coronary heart disease (CHD), stroke, venous thromboembolism (VTE), and a heightened adverse probability of invasive breast cancer. This led to a paradigm shift in HT practice and downgraded estrogen therapy or HT to second-line osteoporosis therapy for postmenopausal women. It is worth noting the limitations of the WHI-HT studies which only studied two hormonal formulations (CEE alone and CEE+MPA), one dosage, and one mode of delivery of estrogen. Moreover, multiple reanalysis of the WHI data stratified women by age and time since onset of menopause with accumulative follow-up reports confirming a "timing hypothesis" suggesting that the benefit of HT outweighs the risk in young postmenopausal women (aged 50-59) [83]. Therefore, HT should not be omitted from the osteoporosis management toolbox and can be considered first-line therapy in special group of women (POI, early menopause, $<10$ years of menopause with coexisting bothersome vasomotor symptoms) without contraindications.

Selective estrogen receptor modulators (SERMs) are another option for the prevention and treatment of osteoporosis in postmenopausal women. SERMs are a unique type of hormonal compound purposefully designed to act as estrogen antagonistsand agonists in various types of tissues through their interactions with intracellular endoplasmic reticulums $[4,84]$. The main type of SERM is raloxifene which can act as both estrogen antagonist and agonist. As with other 
antiresorptive agents, raloxifene decreases bone resorption and turnover thus increasing BMD [4] with its antagonist properties affecting breast and uterine tissue. Raloxifene has been approved by the FDA for osteoporosis treatment and prevention in the form of Evista. The definitive study to evaluate raloxifene comes from the Multiple Outcomes of Raloxifene Evaluation (MORE) study which involved 7,705 postmenopausal women from the ages of 31 to 80 years, all-in-all lasting about 6 years for a complete analysis and evaluation [85]. Either $60 \mathrm{mg} / \mathrm{d}$ or $120 \mathrm{mg} / \mathrm{d}$ dosages of raloxifene was administered to patients along with the typical placebo and additional dosages of calcium and cholecalciferol [85]. Results of the MORE study indicated that vertebral fracture risk was reduced (relative risk $[R R]=0.7$ ), BMD in the femoral neck area was increased by about $2.1 \%$ for the $60 \mathrm{mg} / \mathrm{d}$ dosage and $2.4 \%$ for the $120 \mathrm{mg} / \mathrm{d}$ dosage, and frequency of vertebral fractures was also reduced [85]. Although in the MORE study, raloxifene was shown to increase BMD and reduce vertebral fractures, it should be avoided in premenopausal women, who are pregnant, or postmenopausal women who have a history of venous thromboembolism (VTE) [4]. Other types of SERMs, such as tamoxifen and toremifene initially designed to treat advanced breast cancer have also been demonstrated to have beneficial effects on BMD in postmenopausal women; however, increased risks of cancer such as endometrial cancer with tamoxifen, and hot flashes and sweating as a result of toremifene dosages [84] make these two drugs highly implausible for HT-based osteoporosis treatment. In general, SERMs are less effective than estrogen for osteoporosis prevention and treatment making them a second-line option for HT-based osteoporosis treatments.

Hormonal therapy in men is targeted towards those with hypogonadal osteoporosis. Hypogonadism is a condition where males during puberty do not produce enough of the primary sex hormone, testosterone. This is the most common secondary cause of osteoporosis in men.

Hypogonadism correlates with low BMD from an early age leading to an increased risk of fracture. Many studies have attempted to evaluate effects of testosterone therapy on men with osteoporosis. First, a study by Behre et al. studied 72 patients ranging from 18 to 74 years of age all of whom had various types of hypogonadism including primary hypogonadism, secondary hypogonadism, Klinefelter's syndrome and idiopathic hypogonadotropic hypogonadism, etc [86]. Exogenous testosterone was administered orally, transdermally, or by intramuscular injection [86]. Snyder et al. reported that volumetric BMD (VBMD) and bone strength obtained through QCT along with area BMD assessed by DXA uniformly increased in the trabecular and peripheral bone of the spine and hip through 12 months of testosterone substitution treatment in older men (aged 65 years or older) with low serum testosterone ( $<275 \mathrm{ng} / \mathrm{L}$ ) [87]. In addition, there existed a significant correlation between serum levels of testosterone and BMD such that patients with the lowest initial BMD measurements had the most drastic increase in BMD while taking testosterone treatment. A randomized studyfound that out of a sample size of 48 men over the ages of 60 years with testosterone deficiency (serum testosterone levels $<320 \mathrm{ng} / \mathrm{dL}$ ), testosterone therapy for 12 months resulted in a significant increase in lumbar spine BMD $\left(1.198 \pm 0.153\right.$ to $\left.1.240 \pm 0.141 \mathrm{~g} / \mathrm{cm}^{2}\right)$ [88]. Another RCT reported that long-acting testosterone therapy for 3 years in middle-aged men with late-onset hypogonadism (testosterone $<320 \mathrm{ng} / \mathrm{dL}$ ) significantly increased spine and femoral BMD [89]. It is evident that testosterone therapy in hypogonadal, testosterone-deficient men has the potential to be a highly effective tool for osteoporosis prevention and treatment; however, the anti-fracture effect of testosterone in symptomatic hypogonadal men with low bone mass or osteoporosis remains unclear. The Endocrine Society has recommended testosterone therapy in men with symptomatic androgen deficiency (serum testosterone concentration $<200 \mathrm{ng} / \mathrm{dL}$ ) to 
improve sexual function, sense of well-being and BMD [90]. The Endocrine Society also recommends combination treatment with an agent with proven antifracture efficacy such as bisphosphonate and teriparatide for hypogonadal men who have a high fracture risk [48]. Patients should be monitored every 3 to 6 months after initiation of replacement therapy and annually thereafter [90].

\section{Advances and Future Research Direction}

As more treatments are being developed, tested, and approved for the prevention and treatment of osteoporosis, researchers continue to search for a more optimal osteoporosis therapy. Ever since the development and utilization of the drug denosumab, analysis on bone cells and diseases (specifically, research on the osteoclast) has resulted in emerging drugs that may prove more effective with significantly less negative side effects and perhaps provide amore cost-effective approach to osteoporosis prevention and treatment. This section will summarize, review, and analyze all major updates in advances and research particularly special patient populations of concern, and prospective future research directions.

Romosozumab, sold under the brand name Evenity, was recently approved by the FDA in 2019 for the treatment of osteoporosis in postmenopausal women at very high risk of fracture for up to 1 year; however, women with high risk for CVD and stroke are not candidates for therapy [91]. Romosozumab is a monoclonalantibody that inhibits the protein sclerostin thereby limiting its ability to inhibit bone formation [4]. A FRAME clinical Phase 3 trial tested the effectiveness of romosozumab (210 mg, subcutaneously, then $60 \mathrm{mg}$ biannually for 1 year) on vertebral fractures in 7,180 postmenopausal women whose T-scores were between -2.5 and -3.5 [92]. Results showed that romosozumab reduced vertebral fractures by $73 \%$ by the end of the 12 -month study period [92]. It must be noted that the FDA had initially rejected romosozumab as an osteoporosis therapy agent due to safety concerns; specifically, reactions at the subcutaneous injection site, jaw osteonecrosis, and abnormal femoral fractures. Nevertheless, the recent FDA approval of romosozumab for a specific and high-risk group signals potential value and effectiveness towards osteoporosis treatment, although patients should still be wary of side effects like sudden cardiac arrest and stroke.

Odanacatib is a new drug that selectively inhibits the activity of the enzyme Cathepsin- $K$, a lysosomal protease that degrades type I collagen in bones. Odanacatib was regarded as a fascinating development for osteoporosis treatment because inhibiting CatK activity could decrease bone resorption without decreasing bone formation [4]. Additionally, odanacatib could selectively inhibit the cathepsins $B, S$, and $L$ to avoid any negative side effects such as inflammation and skin reactions. Odanacatib can be administered orally once per week along with adequate vitamin D3 and calcium intake. The leading and most well-known study on the effectiveness of odanacatib on fractures was the Long Term Odanacatib Fracture Trial (LOFT). In this phase III trial, a total of 16,713 postmenopausal women were randomized at 387 centers to $50 \mathrm{mg} /$ day of odanacatib, once per week or a matching placebo. Participants had T-scores $\leq-2.5$ at the total hip or femoral neck or a prior radiographic vertebral fracture and a T-score $\leq-1.5$ at the total hip or femoral neck [93]. Results were taken after 6 and 12 months following the base study closeout. Subsequently 8,256 participants entered the study extension with a plan to take odanacatib for up to 5 years [93]. Regarding radiographic vertebral fractures in the odanacatib group vs. the placebo group, 3.7\% (251) of participants taking odanacatib experienced a vertebral fracture compared to $7.8 \%$ of placebo 
participants [4]. Radiographic vertebral fractures for LOFT plus LOFT extension can be summarized as having a significantly lower incidence of fractures in the odanacatib group compared to placebo, with $4.9 \%$ (341/6909) of odanacatib participants along with $1.1 \%(86 / 8043)$ during the extension suffering continued hip fractures and $6.4 \%$ (512/8043) suffering any other non-vertebral fracture. In 2016, Merck subsequently discontinued production and testing of odanacatib due to risk of stroke, cardiovascular death, and myocardial infarction [4].

Abaloparatide is a subset of a parathyroid hormone-related protein (PTHrP) that is primarily used to treat and prevent osteoporosis. PTH regularly acts as an endocrine regulator of calcium, but PTHrP functions as a mediator of endochondral bone development [94]. Somewhatsimilar to odanacatib, PTHrP could increase bone formation and enhance BMD growth without subsequently stimulating bone resorption [94]. In one study, spineBMD rapidly increased $6 \%$ to $8 \%$ after 3 months of continual dosages of abaloparatide [95]. The Abaloparatide Comparator Trial In Vertebral Endpoints (ACTIVE) was a phase III clinical trial that assessed the change in incidence of vertebral fractures as well as any discrepancy in BMD in 2,463 women (mean age of 69 years) with T-scores between -2.5 and -5.0 at the lumbar spine or femoral neck from March 2011 to October 2014 across 28 sites in 10 countries [96, 97]. Abaloparatide was administered via daily subcutaneous injections of $80 \mu \mathrm{g} /$ day and resulted in a $12.5 \%$ increase in lumbar spine BMD, a $4.8 \%$ increase in femoral neck $B M D$, and a 4.4\% increase in total hip BMD [96]. In all,vertebral fracture rate decreased by a total of $86 \%$ [70]. Abaloparatide was approved by the FDA in 2017 in the form of a $1.56 \mathrm{~mL}$ prefilled pen and was an exciting and novel option for osteoporosis therapy.

Osteoporosis is not only limited to postmenopausal women. Osteoporosis especially affects the livelihood of nursing home residents. Fractures occur at a rate of $>10$ per 100 nursing home residents per year while 25 -hydroxy vitamin $D$ levels are deficient $(<20 \mathrm{ng} / \mathrm{mL})$ in $60 \%$ of residents [98]. What is especially concerning is that many osteoporosis therapies and preventions are underutilized in the nursing home resident population. According to the Systematic Assessment of Geriatric Drug Use via Epidemiology database, only $25 \%$ of nursing home residents with osteoporosis received anti-osteoporosis drugs [99]. A study by Colon-Emeric et al. reported that out of 895 residents investigated throughout 67 study facilities, the frequency of bisphosphonates prescribed was $19 \%$ and of calcitonins was $14 \%$ [98]. All other osteoporosis medications, aside from the above, calcium and vitamin D, were administered to only less than $5 \%$ of the cohort [98]. The complexities of nursing homes are great, but given the expected increase in the aging population, osteoporosis therapy will be urgently needed.

More awareness of osteoporosis prevention and treatment in women with breast cancer is needed. Women with breast cancer can be at higher risk for osteoporosis than postmenopausal women without breast cancer since aromatase inhibitors, chemotherapy-induced ovarian failure and gonadotropin-releasing hormone antagonists all can decrease estrogen levels in women receiving breast cancer treatment. Breast cancer can also increase osteoclast activity and adversely affect BMD [100]. Treatment is more challenging in this population because estrogen therapy for osteoporosis is contraindicated, and other agents such as tamoxifen may decrease BMD or increase fractures. The key to osteoporosis therapy in women with breast cancer may lie with the oral bisphosphonates, zoledronic acid, or denosumab, which could increase BMD in the lumbar spine and the femoral neck. Women with breast cancer should receive 1000-1200 mg/day of calcium (including dietary sources) and 800-1000 IU/day of vitamin D3. BMD should be monitored every two years [101]. 
In addition to new advances in the prevention and treatment of osteoporosis, it is important to analyze the future direction in which treatment could be headed. The following section will summarize a variety of research directions in the field of osteoporosis prevention and treatment, expand on previous evaluations of drugs and introduce novel and ground-breaking therapies and ideas.

The area of genomics is one that could prove to be useful. Classic examples of genomics in osteoporosis treatment comes from Wnt signaling and sclerostin, where inhibiting sclerostin and preventing it from functioning could potentially be effective in increasing BMD and reducing vertebral fractures. However, new studies in the field of genomics have shown that research targets such as LRP4, LRP5/6, WNT16, NOTUM, and others could have a similar inhibitory effect on Wnt signaling as drugs that target sclerostin [102]. NOTUM is a lipase that inhibits Wnt activity through removal of the palmitoleic acid group and in some studies has been tested on laboratory mice demonstrating an increase in cortical BMD and strength. Tools to advance genomics research involve the novel technology CRISPR along with exome, RNA and/or whole genome sequencing [102]. Steps have been taken to understand how genomics can be utilized to treat osteoporosis. The International Bone and Mineral Society has begun to create a detailed skeletal database that would provide valuable information on how genomes can affect BMD, bone strength, and bone mass [102]. Genomics is a fascinating new direction that could be incredibly beneficial towards further attempts to treat and prevent osteoporosis.

Research has shown that combining antiresorptive drugs could potentially be another approach in effectively treating osteoporosis but may be associated with an adynamic state or "frozen bone" [103-105]. Research into either sequential or combining one antiresorptive agent with a PTH analog has yielded hopeful results. The PATH randomized study examined postmenopausal osteoporotic women who took a combination of PTH (1-84) and alendronate for 2 years or PTH for 1 year followed by alendronate for 1 year. The sequential regimen resulted in a significantly higher BMD increase (12.1\%) in lumbar spine and volumetric BMD in trabecular bone compared to the combination regimen. In the second year, women in the PTH-alendronate sequential regimen gained significant BMD at the spine (4.9\%) and hip (3.6\%) [106]. While an anabolic agent teriparatide increases spine BMD more than antiresorptive agent zoledronic acid (ZA) and ZA increases hip BMD more than teriparatide, combining ZA with teriparatide resulted in the largest, most rapid increments in spine and total hip BMD than each agent alone over 1 year of treatment of postmenopausal osteoporosis [107]. According to the DATA Extension Study [108] conducted in postmenopausal women with osteoporosis, combining an antiresorptive agent denosumab with teriparatide for 2 years resulted in the highest increase $(12.9 \pm 5.0 \%)$ in lumbar spine BMD than either denosumab $(8.3 \pm 3.4 \%, P$ $=.008)$ or teriparatide $(9.5 \pm 5.9 \%, P=.01)$ alone. Femoral neck BMD and total hip BMD also increased more in the combination group than either agent alone. The radius along with tibia cortical volumetric BMD, cortical thickness, and bone strength all increased on a greater scale than did the two monotherapies [108]. The higher effectiveness of this combination therapy could be explained by the ability of denosumab to inhibit teriparatide's pro-resorptive effects while also allowing teriparatide to enhance bone formation. Overall, two out of the three of these anabolic and antiresorptive agent combinations (compared to monotherapy) resulted in about the same or a significantly higher total hip BMD gain. Why this is considered a future research direction is the overall unknown nature of this avenue of work, the lack of legitimate fracture data and potential adverse side effects. 
The relationship between the intestinal tract, micro and probiotics, and bone health has been further revealed and understood [109] through previous studies and research. In a study by Sjogren et al. on laboratory mice, gut microbiota was revealed to play a major role in improving bone health by directly reducing osteoclasts and CD4(+) T-cells in the bone [110]. The effect of gut and intestine microbiota does havecontroversy and uncertainty, as some research has shown there was not a difference in BMD between standard mice and mice with gut microbiota, and that acute colonization of gut microbiota can sharply decrease BMD [111]. Adding probiotic bacteria to the already existing intestinal and gut microbiota may become a more effective bacteria-based osteoporosis prevention and treatment strategy. A study performed by McCabe etal. tested the effectiveness of $L$. reuteri ATCC 6475, administered to adult, pathogen-free male mice. Results indicated that oral administration of the probiotic L. reuteri ATCC 6475 resulted in a variety of bone health benefits such as increased femoral and trabecular BMD, trabecular number and thickness, and bone minerals itself in the male mice [111] which can be explained by an increase in osteoblasts and bone formation. Although L. reuteri did not have any conclusive data on its beneficial effect on bone formation, the results above do show that this specific probiotic can positively increase BMD. Various other studies that tested the effectiveness of other probiotics have also been conducted. For instance, probiotic Bifidobacterium longum (ATCC 15707) has been demonstrated to increase essential bone minerals like calcium, phosphorus, and magnesium in the tibia in mice compared to conventional, untreated mice. The probiotic Lactobacillus rhamnosus (HN001) in rats also increased calcium and magnesium retention [111]. Although quantitative data have been collected on the effectiveness and beneficial effects of probiotics on bone health, future research lies in the exact qualities of probiotics, the secretion of peptides, increase in mucus production, and the immune system as those are responsible for the improvement of bone health. Additionally, studies need to be developed to test probiotics on humans which is an unlikely yet still potential prospect.

\section{Conclusion}

The impacts of osteoporosis on the worldwide population cannot be denied. Given the common risk factors such as age, nutrition, menopausal status, and how pervasive the economic and physical burdens of osteoporosis are, it is important to gain clarity and understanding in osteoporosis screening and diagnosis. While a number of non-pharmacological and pharmacological osteoporosis treatments have been approved for use, it is expected that many new advances and drug developments will be included in the growing toolbox of osteoporosis prevention and treatment in the near future.

\section{Author Contributions}

Nathan Jiang: first draft of manuscript; Byron Newton: first reviewer; Xuezhi Jiang: second reviewer and final version of manuscript

\section{Competing Interests}

The authors have declared that no competing interests exist. 


\section{References}

1. Riggs BL, Wahner HW, Seeman E, Offord KP, Dunn WL, Mazess RB, et al. Changes in bone mineral density of the proximal femur and spine with aging: Differences between the postmenopausal and senile osteoporosis syndromes. J Clin Investig. 1982; 70: 716-723.

2. Mirza F, Canalis E. Secondary osteoporosis: Pathophysiology and management. Eur J Endocrinol. 2015; 173: R131-R151.

3. Sözen T, Özışık L, Başaran NÇ. An overview and management of osteoporosis. Eur J Rheumatol. 2017; 4: 46-56.

4. Tu KN, Lie JD, Wan CK, Cameron M, Austel AG, Nguyen JK, et al. Osteoporosis: A review of treatment options. Pharm Ther. 2018; 43: 92-104.

5. Riggs BL. Overview of osteoporosis. West J Med. 1991; 154: 63-77.

6. Dobbs MB, Buckwalter J, Saltzman C. Osteoporosis: The increasing role of the orthopaedist. lowa Orthop J. 1999; 19: 43-52.

7. Cummings SR, Rubin SM, Black D. The future of hip fractures in the United States. Numbers, costs, and potential effects of postmenopausal estrogen. Clin Orthop Relat Res. 1990; 252: 163166.

8. Griffith JF. Identifying osteoporotic vertebral fracture. Quant Imaging Med Surg. 2015; 5: 592602.

9. Williams SA, Daigle SG, Weiss R, Wang Y, Arora T, Curtis JR, et al. ABSTRACT: 0533. Characterization of older male patients with a fragility fracture. Proceedings of the $A C R$ Convergence 2020; 2020 November 7th; Atlanta, GA, USA. Atlanta: American College of Rheumatology.

10. Raisz LG. Pathogenesis of osteoporosis: Concepts, conflicts, and prospects. J Clin Investig. 2005; 115: 3318-3325.

11. Ralston SH, De Crombrugghe B. Genetic regulation of bone mass and susceptibility to osteoporosis. Genes Dev. 2006; 20: 2492-2506.

12. Bainbridge KE, Sowers MF, Crutchfield M, Lin X, Jannausch M, Harlow SD. Natural history of bone loss over 6 years among premenopausal and early postmenopausal women. Am J Epidemiol. 2002; 156: 410-417.

13. Seifert-Klauss V, Link T, Heumann C, Luppa P, Haseitl M, Laakmann J, et al. Influence of pattern of menopausal transition on the amount of trabecular bone loss: Results from a 6-year prospective longitudinal study. Maturitas. 2006; 55: 317-324.

14. Berger C, Langsetmo L, Joseph L, Hanley DA, Davison KS, Josse R, et al. Change in bone mineral density as a function of age in women and men and association with the use of antiresorptive agents. Can Med Assoc J. 2008; 178: 1660-1668.

15. Pouresmaeili F, Kamalidehghan B, Kamarehei M, Goh YM. A comprehensive overview on osteoporosis and its risk factors. Ther Clin Risk Manag. 2018; 14: 2029-2049.

16. Dontas IA, Yiannakopoulos CK. Risk factors and prevention of osteoporosis-related fractures. J Musculoskelet Neuronal Interact. 2007; 7: 268-272.

17. Yoshimura N, Muraki S, Oka H, Morita M, Yamada H, Tanaka S, et al. Profiles of vitamin D insufficiency and deficiency in Japanese men and women: Association with biological, environmental, and nutritional factors and coexisting disorders: The ROAD study. Osteoporos Int. 2013; 24: 2775-2787. 
18. Zhang X, Yu Z, Yu M, Qu X. Alcohol consumption and hip fracture risk. Osteoporos Int. 2015; 26 : 531-542.

19. Hannan MT, Felson DT, Dawson-Hughes B, Tucker KL, Cupples LA, Wilson PW, et al. Risk factors for longitudinal bone loss in elderly men and women: The Framingham osteoporosis study. J Bone Miner Res. 2000; 15: 710-720.

20. Kline J, Tang A, Levin B. Smoking, alcohol and caffeine in relation to two hormonal indicators of ovarian age during the reproductive years. Maturitas. 2016; 92: 115-122.

21. Krall EA, Dawson-Hughes B. Smoking and bone loss among postmenopausal women. J Bone Miner Res. 1991; 6: 331-338.

22. Hernigou J, Schuind F. Tobacco and bone fractures: A review of the facts and issues that every orthopaedic surgeon should know. Bone Jt Res. 2019; 8: 255-265.

23. Morin SN, Lix LM, Leslie WD. The importance of previous fracture site on osteoporosis diagnosis and incident fractures in women. J Bone Miner Res. 2014; 29: 1675-1680.

24. Hardy R, Cooper MS. Bone loss in inflammatory disorders. J Endocrinol. 2009; 201: 309-320.

25. Ilias I, Zoumakis E, Ghayee H. An overview of glucocorticoid induced osteoporosis [Internet]. South Dartmouth: MDText.com, Inc.; 2018. Available from: https://www.ncbi.nlm.nih.gov/books/NBK278968/.

26. Kanis JA. Diagnosis of osteoporosis and assessment of fracture risk. Lancet. 2002; 359: 19291936.

27. Campion JM, Maricic MJ. Osteoporosis in men. Am Fam Physician. 2003; 67: 1521-1526.

28. Laan RF, van Riel PL, van de Putte LB, van Erning $L$, van't Hof MA, Lemmens JA. Low-dose prednisone induces rapid reversible axial bone loss in patients with rheumatoid arthritis: $A$ randomized, controlled study. Ann Intern Med. 1993; 119: 963-968.

29. Dempster DW, Arlot MA, Meunier PJ. Mean wall thickness and formation periods of trabecular bone packets in corticosteroid-induced osteoporosis. Calcif Tissue Int. 1983; 35: 410-417.

30. Vandenput L, Mellström D, Laughlin GA, Cawthon PM, Cauley JA, Hoffman AR, et al. Low testosterone, but not estradiol, is associated with incident falls in older men: The international MrOS study. J Bone Miner Res. 2017; 32: 1174-1181.

31. Mellström D, Johnell O, Ljunggren Ö, Eriksson AL, Lorentzon M, Mallmin $H$, et al. Free testosterone is an independent predictor of $\mathrm{BMD}$ and prevalent fractures in elderly men: MrOS Sweden. J Bone Miner Res. 2006; 21: 529-535.

32. Meier C, Nguyen TV, Handelsman DJ, Schindler C, Kushnir MM, Rockwood AL, et al. Endogenous sex hormones and incident fracture risk in older men: The Dubbo osteoporosis epidemiology study. Arch Intern Med. 2008; 168: 47-54.

33. Auyeung TW, Lee JS, Kwok T, Leung J, Ohlsson C, Vandenput L, et al. Testosterone but not estradiol level is positively related to muscle strength and physical performance independent of muscle mass: A cross-sectional study in 1489 older men. Eur J Endocrinol. 2011; 164: 811817.

34. Garnero P, Sornay-Rendu E, Chapuy MC, Delmas PD. Increased bone turnover in late postmenopausal women is a major determinant of osteoporosis. J Bone Miner Res. 1996; 11: 337-349.

35. Cosman F, Shen V, Xie F, Seibel M, Ratcliffe A, Lindsay R. Estrogen protection against bone resorbing effects of parathyroid hormone infusion: Assessment by use of biochemical markers. Ann Intern Med. 1993; 118: 337-343. 
36. Popat VB, Calis KA, Vanderhoof VH, Cizza G, Reynolds JC, Sebring N, et al. Bone mineral density in estrogen-deficient young women. J Clin Endocrinol Metab. 2009; 94: 2277-2283.

37. Nuti R, Brandi ML, Checchia G, Di Munno O, Dominguez L, Falaschi $P$, et al. Guidelines for the management of osteoporosis and fragility fractures. Intern Emerg Med. 2019; 14: 85-102.

38. Curry SJ, Krist AH, Owens DK, Barry MJ, Caughey AB, Davidson KW, et al. Screening for osteoporosis to prevent fractures: US Preventive Services Task Force recommendation statement. JAMA. 2018; 319: 2521-2531.

39. Crandall CJ, Larson J, Gourlay ML, Donaldson MG, LaCroix A, Cauley JA, et al. Osteoporosis screening in postmenopausal women 50 to 64 years old: Comparison of US Preventive Services Task Force strategy and two traditional strategies in the Women's Health Initiative. J Bone Miner Res. 2014; 29: 1661-1666.

40. Bansal S, Pecina JL, Merry SP, Kennel KA, Maxson J, Quigg S, et al. US Preventative Services Task Force FRAX threshold has a low sensitivity to detect osteoporosis in women ages 50-64 years. Osteoporos Int. 2015; 26: 1429-1433.

41. Jiang X, Good LE, Spinka R, Schnatz PF. Osteoporosis screening in postmenopausal women aged 50-64 years: BMI alone compared with current screening tools. Maturitas. 2016; 83: 59-64.

42. Ghannam S, Blaney H, Gelfond J, Bruder JM. The Use of FRAX in identifying women less than 65 years needing bone mineral density testing. J Clin Densitom. 2021; 24: 36-43.

43. Cosman F, de Beur SJ, LeBoff MS, Lewiecki EM, Tanner B, Randall S, et al. Clinician's guide to prevention and treatment of osteoporosis. Osteoporos Int. 2014; 25: 2359-2381.

44. Lydick E, Cook K, Turpin J, Melton M, Stine R, Byrnes C. Development and validation of a simple questionnaire to facilitate identification of women likely to have low bone density. Am J Manag Care. 1998; 4: 37-48.

45. Koh LK, Sedrine WB, Torralba TP, Kung A, Fujiwara S, Chan SP, et al. A simple tool to identify Asian women at increased risk of osteoporosis. Osteoporos Int. 2001; 12: 699-705.

46. Subramaniam S, Ima-Nirwana S, Chin KY. Performance of osteoporosis self-assessment tool (OST) in predicting osteoporosis-a review. Int J Environ Res Public Health. 2018; 15: 1445.

47. Kanis JA, Harvey NC, Cooper C, Johansson H, Odén A, McCloskey EV. A systematic review of intervention thresholds based on FRAX. Arch Osteoporos. 2016; 11: 25.

48. Watts NB, Adler RA, Bilezikian JP, Drake MT, Eastell R, Orwoll ES, et al. Osteoporosis in men: An Endocrine Society clinical practice guideline. J Clin Endocrinol Metab. 2012; 97: 1802-1822.

49. Kanis JA, Melton III LJ, Christiansen C, Johnston CC, Khaltaev N. The diagnosis of osteoporosis. J Bone Miner Res. 1994; 9: 1137-1141.

50. Bernabei R, Martone AM, Ortolani E, Landi F, Marzetti E. Screening, diagnosis and treatment of osteoporosis: A brief review. Clin Cases Miner Bone Metab. 2014; 11: 201-207.

51. Damilakis J, Adams JE, Guglielmi G, Link TM. Radiation exposure in X-ray-based imaging techniques used in osteoporosis. Eur Radiol. 2010; 20: 2707-2714.

52. Cummings SR, Browner W, Black DM, Nevitt MC, Genant HK, Cauley J, et al. Bone density at various sites for prediction of hip fractures. Lancet. 1993; 341: 72-75.

53. Balasubramanian A, Zhang J, Chen L, Wenkert D, Daigle SG, Grauer A, et al. Risk of subsequent fracture after prior fracture among older women. Osteoporos Int. 2019; 30: 79-92.

54. Dawson-Hughes B, Tosteson AN, Melton L3, Baim S, Favus MJ, Khosla S, et al. Implications of absolute fracture risk assessment for osteoporosis practice guidelines in the USA. Osteoporos Int. 2008; 19: 449-458. 
55. Kanis JA, Oden A, McCloskey EV, Johansson H, Wahl DA, Cooper C. A systematic review of hip fracture incidence and probability of fracture worldwide. Osteoporos Int. 2012; 23: 2239-2256.

56. Kanis JA, Cooper C, Dawson-Hughes B, Harvey NC, Johansson H, Lorentzon M, et al. FRAX and ethnicity. Osteoporos Int. 2020; 31: 2063-2067.

57. Jiang $X$, Gruner $M$, Trémollieres F, Pluskiewicz W, Sornay-Rendu E, Adamczyk $P$, et al. Diagnostic accuracy of FRAX in predicting the 10-year risk of osteoporotic fractures using the USA treatment thresholds: A systematic review and meta-analysis. Bone. 2017; 99: 20-25.

58. McCloskey EV, Odén A, Harvey NC, Leslie WD, Hans D, Johansson H, et al. A meta-analysis of trabecular bone score in fracture risk prediction and its relationship to FRAX. J Bone Miner Res. 2016; 31: 940-948.

59. Hans D, Šteňová E, Lamy O. The trabecular bone score (TBS) complements DXA and the FRAX as a fracture risk assessment tool in routine clinical practice. Curr Osteoporos Rep. 2017; 15: 521-531.

60. Martineau $P$, Leslie WD, Johansson $H$, Oden A, McCloskey EV, Hans D, et al. Clinical utility of using lumbar spine trabecular bone score to adjust fracture probability: The Manitoba BMD cohort. J Bone Miner Res. 2017; 32: 1568-1574.

61. Brett AD, Brown JK. Quantitative computed tomography and opportunistic bone density screening by dual use of computed tomography scans. J Orthop Translat. 2015; 3: 178-184.

62. Genant HK, Engelke K, Prevrhal S. Advanced CT bone imaging in osteoporosis. Rheumatology. 2008; 47: iv9-iv16.

63. Marshall LM, Lang TF, Lambert LC, Zmuda JM, Ensrud KE, Orwoll ES. Dimensions and volumetric BMD of the proximal femur and their relation to age among older US men. J Bone Miner Res. 2006; 21: 1197-1206.

64. Hodges JK, Cao S, Cladis DP, Weaver CM. Lactose intolerance and bone health: The challenge of ensuring adequate calcium intake. Nutrients. 2019; 11: 718.

65. Malihi Z, Wu Z, Stewart AW, Lawes CM, Scragg R. Hypercalcemia, hypercalciuria, and kidney stones in long-term studies of vitamin $D$ supplementation: A systematic review and metaanalysis. Am J Clin Nutr. 2016; 104: 1039-1051.

66. Paterson DH, Warburton DE. Physical activity and functional limitations in older adults: A systematic review related to Canada's Physical Activity Guidelines. Int J Behav Nutr Phys Act. 2010; 7: 38.

67. Augestad LB, Schei B, Forsmo S, Langhammer A, Flanders WD. The association between physical activity and forearm bone mineral density in healthy premenopausal women. J Womens Health. 2004; 13: 301-313.

68. Snow-Harter C, Bouxsein M, Lewis B, Charette S, Weinstein P, Marcus R. Muscle strength as a predictor of bone mineral density in young women. J Bone Miner Res. 1990; 5: 589-595.

69. Kanis JA, Johansson $H$, Johnell $O$, Oden A, De Laet $C$, Eisman JA, et al. Alcohol intake as a risk factor for fracture. Osteoporos Int. 2005; 16: 737-742.

70. Khosla S, Hofbauer LC. Osteoporosis treatment: Recent developments and ongoing challenges. Lancet Diabetes Endocrinol. 2017; 5: 898-907.

71. Ringe JD, Farahmand $P$, Faber $H$, Dorst $A$. Sustained efficacy of risedronate in men with primary and secondary osteoporosis: Results of a 2-year study. Rheumatol Int. 2009; 29: 311-315.

72. Eastell R, Rosen CJ, Black DM, Cheung AM, Murad MH, Shoback D. Pharmacological management of osteoporosis in postmenopausal women: An Endocrine Society clinical practice 
guideline. J Clin Endocrinol Metab. 2019; 104: 1595-1622.

73. Ruza I, Mirfakhraee S, Orwoll E, Gruntmanis U. Clinical experience with intravenous zoledronic acid in the treatment of male osteoporosis: Evidence and opinions. Ther Adv Musculoskelet Dis. 2013; 5: 182-198.

74. Cummings SR, Martin JS, McClung MR, Siris ES, Eastell R, Reid IR, et al. Denosumab for prevention of fractures in postmenopausal women with osteoporosis. N Engl J Med. 2009; 361: 756-765.

75. Kalra S, Grimer RJ, Spooner D, Carter SR, Tillman RM, Abudu A. Radiation-induced sarcomas of bone: Factors that affect outcome. J Bone Joint Surg Br Vol. 2007; 89: 808-813.

76. Newhauser WD, Durante M. Assessing the risk of second malignancies after modern radiotherapy. Nat Rev Cancer. 2011; 11: 438-448.

77. Forteo. Indianapolis: Eli Lilly and Company; 2019.

78. Cauley JA, Robbins J, Chen Z, Cummings SR, Jackson RD, LaCroix AZ, et al. Effects of estrogen plus progestin on risk of fracture and bone mineral density: The Women's Health Initiative randomized trial. JAMA. 2003; 290: 1729-1738.

79. Anderson GL, Limacher M, Assaf AR, Bassford T, Beresford SA, Black H, et al. Effects of conjugated equine estrogen in postmenopausal women with hysterectomy: The Women's Health Initiative randomized controlled trial. JAMA. 2004; 291: 1701-1712.

80. Lindsay R, Tohme JF. Estrogen treatment of patients with established postmenopausal osteoporosis. Obstet Gynecol. 1990; 76: 290-295.

81. Ettinger B, Ensrud KE, Wallace R, Johnson KC, Cummings SR, Yankov V, et al. Effects of ultralowdose transdermal estradiol on bone mineral density: A randomized clinical trial. Obstet Gynecol. 2004; 104: 443-451.

82. Rossouw JE, Anderson GL, Prentice RL, LaCroix AZ, Kooperberg C, Stefanick ML, et al. Risks and benefits of estrogen plus progestin in healthy postmenopausal women: Principal results from the Women's Health Initiative randomized controlled trial. JAMA. 2002; 288: 321-333.

83. Jiang XD. Hormone therapy for the treatment of postmenopausal osteoporosis: Will it soon become a lost art in medicine? Menopause. 2018; 25: 723-727.

84. Gennari L, Merlotti D, Nuti R. Selective estrogen receptor modulator (SERM) for the treatment of osteoporosis in postmenopausal women: Focus on lasofoxifene. Clin Interv Aging. 2010; 5: 19-29.

85. Ettinger B, Black DM, Mitlak BH, Knickerbocker RK, Nickelsen T, Genant HK, et al. Reduction of vertebral fracture risk in postmenopausal women with osteoporosis treated with raloxifene: Results from a 3-year randomized clinical trial. JAMA. 1999; 282: 637-645.

86. Behre HM, Kliesch S, Leifke E, Link TM, Nieschlag E. Long-term effect of testosterone therapy on bone mineral density in hypogonadal men. J Clin Endocrinol Metab.1997; 82: 2386-2390.

87. Snyder PJ, Kopperdahl DL, Stephens-Shields AJ, Ellenberg SS, Cauley JA, Ensrud KE, et al. Effect of testosterone treatment on volumetric bone density and strength in older men with low testosterone: A controlled clinical trial. JAMA Intern Med. 2017; 177: 471-479.

88. Basurto L, Zarate A, Gomez R, Vargas C, Saucedo R, Galván R. Effect of testosterone therapy on lumbar spine and hip mineral density in elderly men. Aging Male. 2008; 11: 140-145.

89. Aversa A, Bruzziches R, Francomano D, Greco EA, Fornari R, Luigi LD, et al. Effects of long-acting testosterone undecanoate on bone mineral density in middle-aged men with late-onset hypogonadism and metabolic syndrome: Results from a 36 months controlled study. Aging 
Male. 2012; 15: 96-102.

90. Bhasin S, Cunningham GR, Hayes FJ, Matsumoto AM, Snyder PJ, Swerdloff RS, et al. Testosterone therapy in men with androgen deficiency syndromes: An Endocrine Society clinical practice guideline. J Clin Endocrinol Metab. 2010; 95: 2536-2559.

91. Shoback D, Rosen CJ, Black DM, Cheung AM, Murad MH, Eastell R. Pharmacological management of osteoporosis in postmenopausal women: An endocrine society guideline update. J Clin Endocrinol Metab. 2020; 105: 587-594.

92. Cosman F, Crittenden DB, Adachi JD, Binkley N, Czerwinski E, Ferrari S, et al. Romosozumab treatment in postmenopausal women with osteoporosis. N Engl J Med. 2016; 375: 1532-1543.

93. Bone HG, Dempster DW, Eisman JA, Greenspan SL, McClung MR, Nakamura T, et al. Odanacatib for the treatment of postmenopausal osteoporosis: Development history and design and participant characteristics of LOFT, the Long-Term Odanacatib Fracture Trial. Osteoporos Int. 2015; 26: 699-712.

94. Leder BZ, O'Dea LS, Zanchetta JR, Kumar P, Banks K, McKay K, et al. Effects of abaloparatide, a human parathyroid hormone-related peptide analog, on bone mineral density in postmenopausal women with osteoporosis. J Clin Endocrinol Metab. 2015; 100: 697-706.

95. Horwitz MJ, Tedesco MB, Sereika SM, Garcia-Ocaña A, Bisello A, Hollis BW, et al. Safety and tolerability of subcutaneous PTHrP (1-36) in healthy human volunteers: A dose escalation study. Osteoporos Int. 2006; 17: 225-230.

96. Moreira CA, Fitzpatrick LA, Wang Y, Recker RR. Effects of abaloparatide-SC (BA058) on bone histology and histomorphometry: The ACTIVE phase 3 trial. Bone. 2017; 97: 314-319.

97. Miller PD, Hattersley G, Riis BJ, Williams GC, Lau E, Russo LA, et al. Effect of abaloparatide vs placebo on new vertebral fractures in postmenopausal women with osteoporosis: $A$ randomized clinical trial. JAMA. 2016; 316: 722-733.

98. Colon-Emeric C, Lyles KW, Levine DA, House P, Schenck A, Gorospe J, et al. Prevalence and predictors of osteoporosis treatment in nursing home residents with known osteoporosis or recent fracture. Osteoporos Int. 2007; 18: 553-559.

99. Rojas-Fernandez CH, Lapane KL, MacKnight C, Howard KA. Undertreatment of osteoporosis in residents of nursing homes: Population-based study with use of the Systematic Assessment of Geriatric Drug Use via Epidemiology (SAGE) database. Endocr Pract. 2002; 8: 335-342.

100. Mincey BA, Moraghan TJ, Perez EA. Prevention and treatment of osteoporosis in women with breast cancer. Mayo Clin Proc. 2000; 75: 821-829.

101. Hadji P, Aapro MS, Body JJ, Gnant M, Brandi ML, Reginster JY, et al. Management of Aromatase Inhibitor-Associated Bone Loss (AIBL) in postmenopausal women with hormone sensitive breast cancer: Joint position statement of the IOF, CABS, ECTS, IEG, ESCEO, IMS, and SIOG. J Bone Oncol. 2017; 7: 1-12.

102.Brommage R. Genetic approaches to identifying novel osteoporosis drug targets. J Cell Biochem. 2015; 116: 2139-2145.

103.Odvina CV, Zerwekh JE, Rao DS, Maalouf N, Gottschalk FA, Pak CY. Severely suppressed bone turnover: A potential complication of alendronate therapy. J Clin Endocrinol Metab. 2005; 90 : 1294-1301.

104.Rosen HN, Drezner MK. Menopausal hormone therapy in the prevention and treatment of osteoporosis [Internet]. Waltham: UpToDate; 2021 [cited 2021 May 4th]. Available from: https://www.uptodate.com/contents/postmenopausal-hormone-therapy-in-the-prevention- 
and-treatment-of-osteoporosis.

105.Gallagher JC, Tella SH. Anti-resorptive therapy for preventing bone loss: When to use one or two anti-resorptive agents? Clin Obstet Gynecol. 2013; 56: 749-756.

106.Black DM, Bilezikian JP, Ensrud KE, Greenspan SL, Palermo L, Hue T, et al. One year of alendronate after one year of parathyroid hormone (1-84) for osteoporosis. Obstet Gynecol Surv. 2006; 61: 34-35.

107. Cosman F, Eriksen EF, Recknor C, Miller PD, Guañabens N, Kasperk C, et al. Effects of intravenous zoledronic acid plus subcutaneous teriparatide [rhPTH (1-34)] in postmenopausal osteoporosis. J Bone Miner Res. 2011; 26: 503-511.

108. Leder BZ, Tsai JN, Uihlein AV, Burnett-Bowie SA, Zhu Y, Foley K, et al. Two years of Denosumab and teriparatide administration in postmenopausal women with osteoporosis (the data extension study): A randomized controlled trial. Lancet. 2013; 382: 50-56.

109.Hsu E, Nanes M. Advances in treatment of glucocorticoid-induced osteoporosis. Curr Opin Endocrinol Diabetes Obes. 2017; 24: 411-417.

110.Sjögren K, Engdahl C, Henning P, Lerner UH, Tremaroli V, Lagerquist MK, et al. The gut microbiota regulates bone mass in mice. J Bone Miner Res. 2012; 27: 1357-1367.

111.Collins FL, Rios-Arce ND, Schepper JD, Parameswaran N, McCabe LR. The potential of probiotics as a therapy for osteoporosis. Microbiol Spectr. 2017; 5: 5.4.20.

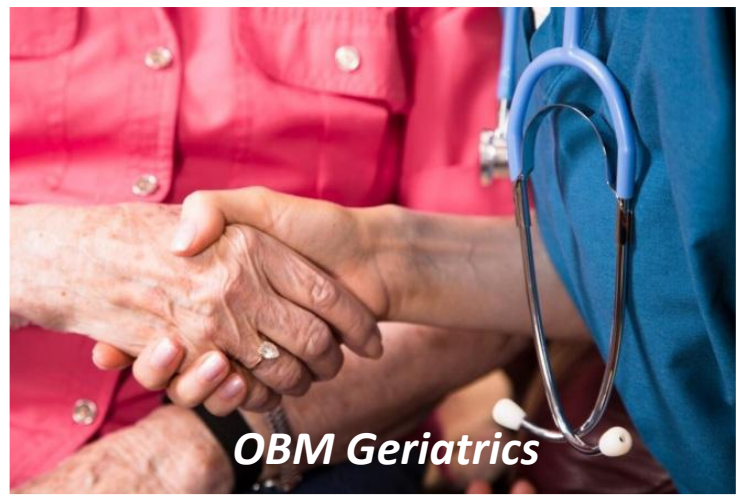

Enjoy OBM Geriatrics by:

1. Submitting a manuscript

2. Joining in volunteer reviewer bank

3. Joining Editorial Board

4. Guest editing a special issue

For more details, please visit:

http://www.lidsen.com/journals/geriatrics 